"The submitted manuscript has been authored by a contractor of the U.S. Goversment under contract No. DE-AC05-84OR21400.

Accordingly, the U.S. Government retains a nonexclusive, royalty-free license to publish or reproduce the published form of this contribution, or allow others to do so, for U.S. Government purposes."

\title{
SPONTANEOUS QUENCHES OF A HIGH TEMPERATURE SUPERCONDUCTING PANCAKE COIL*
}

J. W. Lue and M. S. Lubell

Oak Ridge National laboratory

Oak Ridge, TN 37831-8071

D. Aized, J. M. Campbell, and R. E. Schwall American Superconductor Corp.

Westborough, MA

\section{Presented at \\ 14th International Conference on Magnet Technology \\ Tampere, Finland \\ June $11 \cdot 16,1995$}

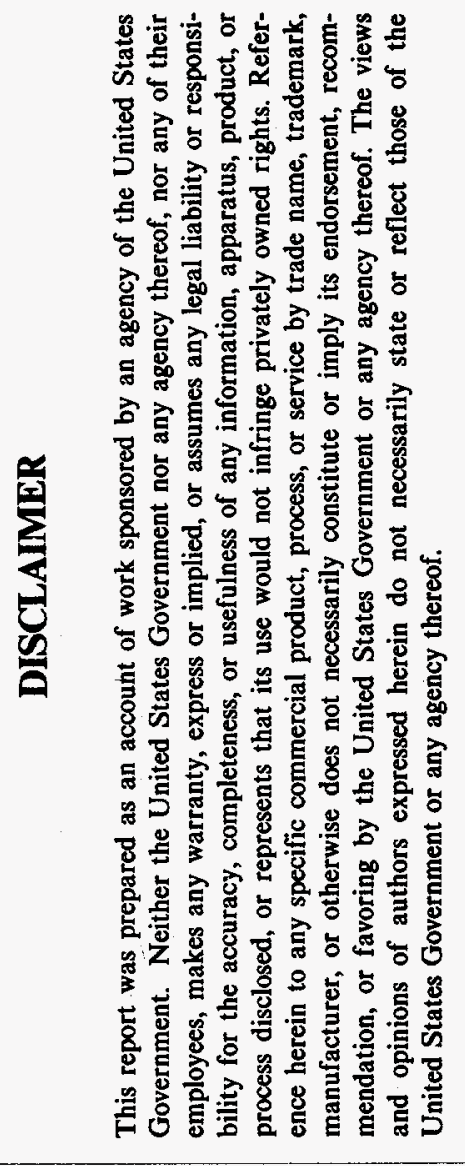

Fusion Energy Division

Oak Ridge National Laboratory

Post Office Box 2008

Oak Ridge, TN 37831-6285 USA Managed by

LOCKHEED MARTIN ENERGY SYSTEMS, INC. for the

U.S. DEPARTMENT OF ENERGY

under contract DE-AC05-84OR21400

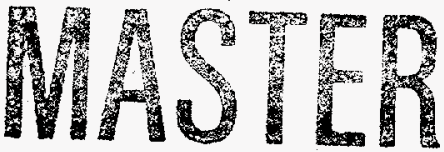

Research sponsored by the Office of Fusion Energy, U.S. Department of Energy, under contract DE-AC05-84OR21400 with Lockheed Martin Energy Systems, Inc. 


\section{DISCLAIMER}

Portions of this document may be illegible in electronic image products. Images are produced from the best available original document. 


\title{
Spontaneous Quenches of a High Temperature Superconducting Pancake Coil
}

\author{
J. W. Lue and M. S. Lubell \\ Oak Ridge National Laboratory, Oak Ridge, TN 37831-8040, USA \\ D. Aized, J. M. Campbell, and R. E. Schwall \\ American Superconductor Corporation, Westborough, MA 01581, USA
}

\begin{abstract}
A double-pancake coil made of Bi-2223/Ag high temperature superconducting (HTS) tape was constructed with an embedded heater and graded conductors to study the stability and quench propagation in HTS coik The experiments were performed with liquid nitrogen and gaseous helium cooling in temperatures ranging from 5 to $77 \mathrm{~K}$. The coil was very stable, and no "norrnal" zone was sustained or propagated with local pulsed heating However, spontaneous quenches of the coil were experienced. This was found to be the result of having the coil current higher than that of the lower $I_{c}$ sections of the coil for a long time This quench process took minutes to develop - much longer than would be expected in a low temperature superconducting coil. The quench behaved more like a spreading and continuous heating of an increasingly larger partially resistive section of the coil than like a sequential "normal" front propagation.
\end{abstract}

\section{INTRODUCTION}

As an ongoing effort to develop high temperature superconducting (HTS) coils for power applications, a double-pancake coil made of $\mathrm{Bi}-2223 / \mathrm{Ag}$ tape was constructed to study the stability and quench propagation in HTS coils. An embedded heater inside the winding and voltage taps on successive turns surrounding the heater were used for these experiments.

Since the current-carrying capability of a superconductor is a function of magnetic field, a common practice is to grade the conductor in a low temperature superconducting (LTS) coil so that fewer superconductors are used in lower field sections of a coil. Because HTS tapes are still very expensive to make, it would be advantageous if a similar grading technique can be used in a HTS coil. This task was attempted in the current work by winding a two-tape conductor bundle for the inner turns and grading to a single-tape conductor for the outer turns of the coil This approach also provided built-in lower $I_{c}$ sections to study the effect on the quench protection of an HTS coil of the often seen nonuniform HTS tapes in long lengths.'

\section{COIL CONSTRUCTION AND INSTRUMENTATION}

The double-pancake coil was built with $\mathrm{Bi}-2223 / \mathrm{Ag}$ tape made by a metallic precursor process. ${ }^{2}$ The $0.16-\mathrm{mm}$ thick by $5.33-\mathrm{mm}$

Mamuscript received June 11, 1995

This work was sporsored by the Office of Energy Efriciency and Renewable Energy, U. S. Deparimene of Energy under contract DE-ACO5.840R21 400 with Martin Marieta Enengy Syatem, Inc (MMES). A portion of the work as American Superoonductor Corporation (ASC) was funded by supereonductivity cocperative agreened mumber 86X-SK700V berween MMES and ASC. wide tape was reacted before winding onto a $25.4-\mathrm{mm}$ bobbin. A contimuous 22-m length of a 2-tape conductor bundle was used to wind the inner 70 turns on each pie of the double-pancake. It was then graded to a l-tape conductor, and another 32 turns (8-m long) were wound for the rest of each of the pies. Thus, the total length of the conductor for the double-pancake was $38 \mathrm{~m}$. The turns were insulated with $0.0635-\mathrm{mm}$ thick, epoxy impregnated paper. The finished double-pancake has a winding OD of $87 \mathrm{~mm}$.

Fig. 1 shows the instrumentation used to study the stability and quench behavior of the coil. A $51-\mathrm{mm}$ long $(5 \Omega)$ foil heater was sandwiched between the 2-tape conductor bundle at the crossover section of the two pancakes. Voltage taps (QA1 - QAS and QB1 $-Q B 3)$ on the successive turns next to the heater were applied to monitor the "normal" voitages of the conductor. The length of the crossover section QAl-QB1 is $243 \mathrm{~mm}$ and that between successive turns is about $84 \mathrm{~mm}$ each. The entire winding was enclosed in a G-10 casing.

\section{STABILITY MEASUREMENTS}

Stability of the coil was measured in $\mathrm{LN}_{2}$ at $77 \mathrm{~K}$ and with helium gas cooling at 20 to $40 \mathrm{~K}$ in a variable temperature cryostat. The coil was charged to a specified current and held while a heating pulse was applied to the resistive heater and the voltages surrounding the heated zone were monitored. Fig. 2 shows an example of the conductor voltage responses for a shot at $20 \mathrm{~K}$ with the coil current held at $40 \mathrm{~A}$. The heated zone QA1QB1 voltage went up to $3.3 \mathrm{mV}$ (as compared to $0.024 \mathrm{mV} @ I_{c}$, defined by the $1-\mu \mathrm{V} / \mathrm{cm}$ criterion) during the heating and disappeared in less than $1 \mathrm{~s}$ after the heat was removed. The voltage over QA5-QB3, which covered several additional turns, showed

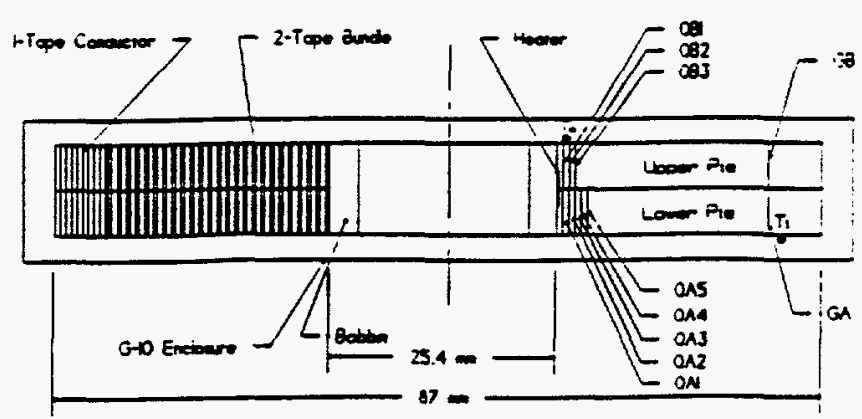

Fig. 1 The double-pancake coil and its instrumentation layour. Voltage taps for the stability measurements were labeled with " $Q$ " and it the grading points were labeled with "G". 


\section{B. Delayed Quench at a Given Current}

The preceding observation sems to indicate that if an HTS coil is charged and held for a sufficiently long time at a current higher than the critical currents of weak spots, a quench could develop. This thought is investigated further during this series of experiments. Fig. 5(a) shows the coil current and voitage traces for a test run at $6 \mathrm{~K}$. The coil was charged to $50 \mathrm{~A}$ in about $210 \mathrm{~s}$ and held at that current. According to Fig. 4, this current is lower than the critical current of the inner turns but higher than that of the outer turns of 1-tape conductor. Little coil voitage change was seen for the next $160 \mathrm{~s}$. Then it increased rapidly, reaching a level of abour $5.5 \mathrm{~V}$ in another $15 \mathrm{~s}$. The coil current dropped to about $20 \mathrm{~A}$ at the same time. No operator action was taken during this period of time. The coil quenched spontaneousiy and its voltage rise was limited only by the $6-\mathrm{V}$ power supply compliance limitation. This action caused the coil voltage to stop at $5.7 \mathrm{~V}$ and the coil current to drop. Manual discharge of the coil was finally implemented after $530 \mathrm{~s}$.

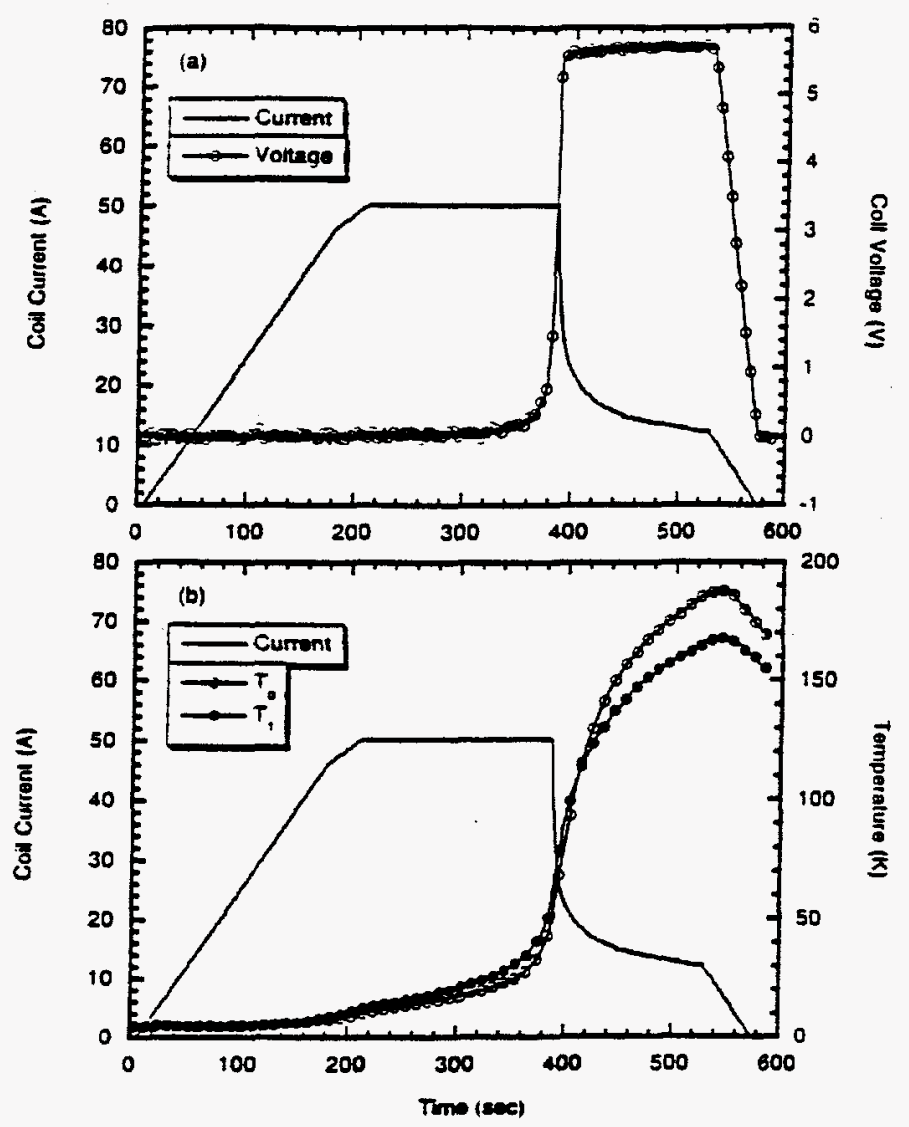

Fig 5 Coil aureser, voltagen and temperature traces of a current change that stanted at a coil temperature of $6 \mathrm{~K}$. Thermomerer $T$. is located at the ID of the coil, and $T$, is located at the grading poirs.
Fig. 5(b) shows the thermometer readings of the coil. A small and steady temperature rise (about $0.15 \mathrm{~K} / \mathrm{s}$ ) was seen on both thermometers after the current reached $50 \mathrm{~A}$. Surprisingiy, only a very small temperature difference existed between the $\mathbb{D}$ and the grading point of the coil. The temperature at the grading point, $T_{1}$, was about $8 \mathrm{~K}$ higher than that at $\mathbb{D} \mathrm{T}_{0}$ by $370 \mathrm{~s}$, the time at which the coil voltage began to rise sharply. The average coil temperature was then about $35 \mathrm{~K}$. At this temperature, the coil current had far excoeded the critical current of even the inner 2-tape conductor turns. The coil temperature also began to rise sharply at this time. Thus, we saw a gradual temperature rise followed by a rapid voltage and temperature rise of the coil when it quenched. Maximum temperatures of $188 \mathrm{~K}$ at the $\mathbb{D}$ and of $168 \mathrm{~K}$ at the grading point were recorded. The poorer cooling condition at the $\mathbb{D}$ was probably the main reason for the higher temperanure that was reached there after the coil quenched. Note that the coil temperature continued to rise rapidiy even after the current had dropped below $20 \mathrm{~A}$ - a result of the $110 \mathrm{~W}$ of heating still generated in the coil at this current.

Similar delaved quench behavior were observed at other test runs with coil starting temperatures ranging from 20 to $77 \mathrm{~K}$.

\section{Quench Development}

To find out the source of the heat and the nature of the quench, let us examine the voltage signals of different sections of the coil. Fig. 6(a) shows the voltage excursions of the five different sections of the coil. At about $150 \mathrm{~s}$, when the coil current reached $38 \mathrm{~A}$, voltages on the two 1 -tape conductor sections, ( + )-GA and GB-(-), began to increase. They continued to increase after the current reached and was held at $50 \mathrm{~A}$. The rate of increase accelerated with time. The voltages of these two sections saturated the amplifier at $0.1 \mathrm{~V}$ at about $350 \mathrm{~s}$. No noticeable voltages were seen in the 2-tape conductor sections (GA-QA5, $\mathrm{QA5}-\mathrm{QB3}$, and QB3-GB) during this time. Thus, up to this point the termperanure rise of the coil shown in Fig. 5(b) was due entireiy to the joule heating in the 1-tape conductor sections. Apparentiy, the heat had been spread throughout the whole coil. Assuming that the joule heating of the 1 -tape section was adiabatically and radialiy (neglecting the much longer path along the conductor) conducted toward the $\mathbb{I D}$, the temperature difference observed in Fig. S(b) between $T_{1}$ and $T_{0}$ indicated an effective radial thermal conductivity of about $0.3 \mathrm{~W} / \mathrm{cm}-\mathrm{K}$ for the current winding pack, which is about $1 / 10$ of that for silver at this temperature range.

The 2-tape conductor sections began to show appreciable voltages only at about $350 \mathrm{~s}$, after the coil temperature had reached $30 \mathrm{~K}$. The voltage increase accelerated and the coil was quenched shortly. When the coil voltage reached the power supply compliance limit, the current started to decrease and the inductive voltage dipped at $385 \mathrm{~s}$. We saw no distinctive and successive propagation of the "normal" front from the 1-tape section to the 2-tape section in this quench development process. 


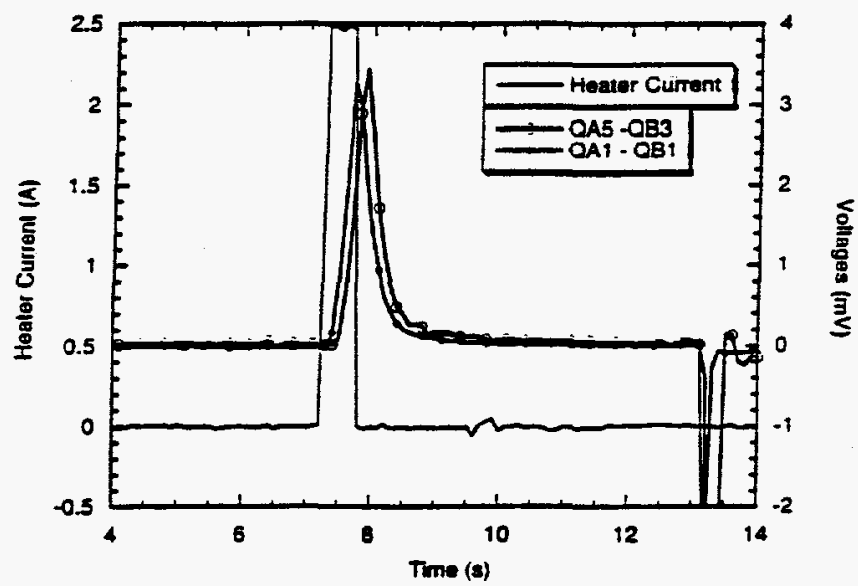

Fig 2 Conductor voltage rexponses to a heating pulse at $20 \mathrm{~K}$ with the coil current holding at $40 \mathrm{~A}$. Coil current whe discharged at 13 s.

that a small voltage that expanded to the adjacent turns also disappeared after the heat was removed. The negative voltages at 13-13.5 s was due to the inductive voltage when the coil current was discharged. In all of the pulse heating shots, no resistive voltage was sustained or expanded with up to $18 \mathrm{~J}$ of heating applied in up to $0.6 \mathrm{~s}$. Thus, the coil was stable against local heating of more than $200 \mathrm{~J} / \mathrm{cm}^{3}-2$ to 3 orders of magnitude higher than in a LTS coil. This result is similar to that measured and reported in more detail on a 1-T HTS magnet. ${ }^{3}$

\section{SPONTANEOUS QUENCHES}

The coil, however, experienced spontaneous quenches, first unexpectedly in a critical current measurement at $20 \mathrm{~K}$. During this series of experiments, only the voltages near the inner turns, which received the highest self-fields, were being monitored (and because $T_{0}$ was broken at the time, the temperature was monitored by a thermometer attached to the outside of the coil case). Fig. 3 shows that the coil was charged to $48 \mathrm{~A}$ in about $420 \mathrm{~s}$ and developed $260 \mu \mathrm{V}$ in section QA5 -QB3 (as compared to $75 \mu \mathrm{V}$ @. I for this section). When the current was being ramped down to about $46 \mathrm{~A}$, it dropped sharply and the voltage went negative. The coil had quenched spontaneously. Also the voltage in section QA5 -QB3 was decreasing smoothly before the quench. Thus, the quench did not start from the inner high field turns. Then, the quench was thought to originate from the l-tape conductor section. Similar spontaneous quenches were experienced at other temperatures from 5 to $40 \mathrm{~K}$.

\section{INVESTIGATION OF THE QUENCH BEHAVIOR}

Additional voltage taps, GA and GB, were added to the conductor grading points of the double pancake. As is shown in Fig. 1, an $\mathrm{RO}_{2}$-thermometer was placed at the winding $\mathrm{D}\left(\mathrm{T}_{0}\right)$, and another one $\left(T_{1}\right)$ was added at the grading point of the lower pie. A second series of experiments was performed to pinpoint the source of the spontaneous quench and to investigate the quench propagation behavior of the coil.

\section{A. Critical Currents}

Since the coil generates significant self-fields $(64 \mathrm{G} / \mathrm{A}$ at the ID) and there is conductor grading, the critical current of the conductor can be quite different at different sections of the coil. Using the $1-\mu \mathrm{V} / \mathrm{cm}$ criterion, the critical currents of the coil, the imer-turns section, QA5-QB3, and the 1-tape conductor section of the lower pie, (t)-GA, were measured and plotted in Fig. 4 as a function of temperature. Although the inner turns conductor had 2-tape thickness, because of the higher seif-field, its $I_{e}$ was only $40 \%$ to $50 \%$ higher than the outer turns. In the run that led to a spontaneous quench, shown in Fig.3, the coil was charged above the $I_{c}$ of both (+)-GA (32 A) and QA5-QB3 (44 A), although it stayed much longer above the $I_{c}$ of $(+)-G A$.

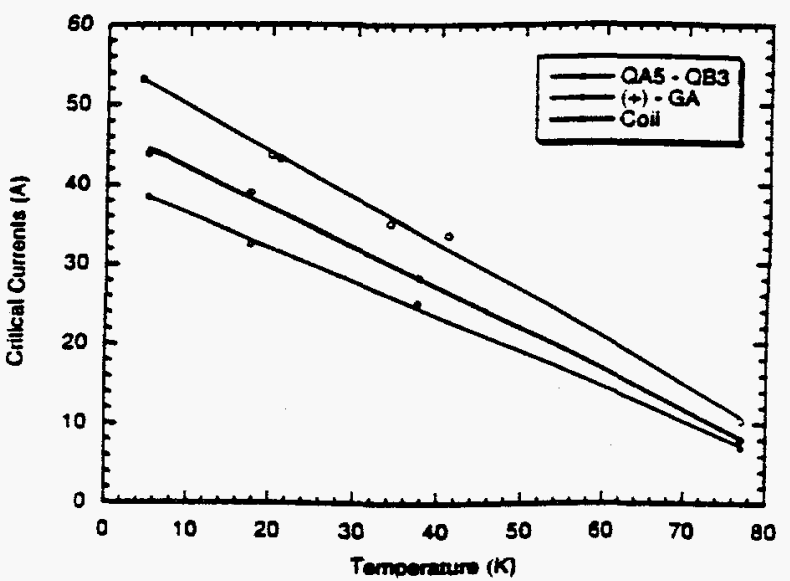

Fig 4 Critical curratis of differem sections of the coil and the whole coil as a function of tempersure determined by the $1 \mu \mathrm{V} / \mathrm{cm}$ criverion

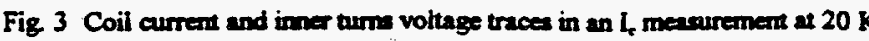

The coil auffered a spostrocous quench at $46 \mathrm{~A}$ after it was charged to $48 \mathrm{~A}$

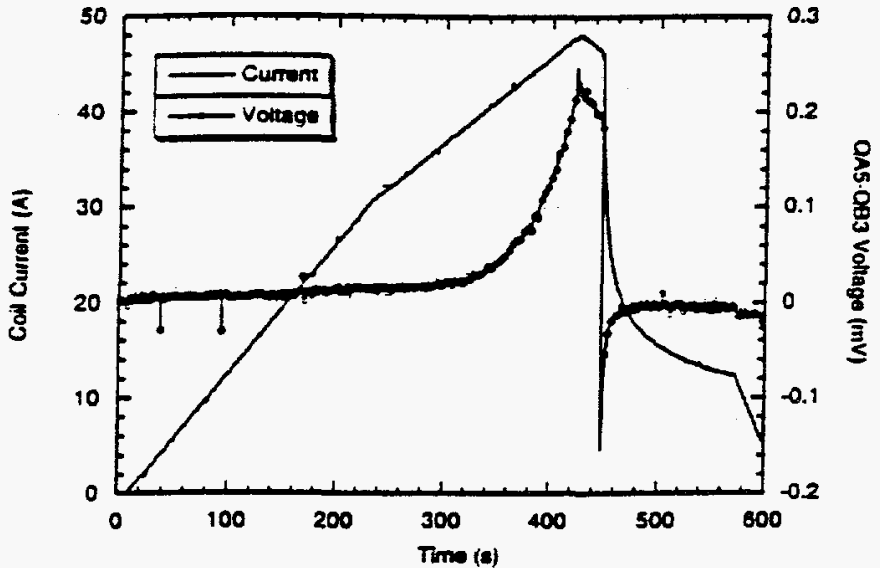




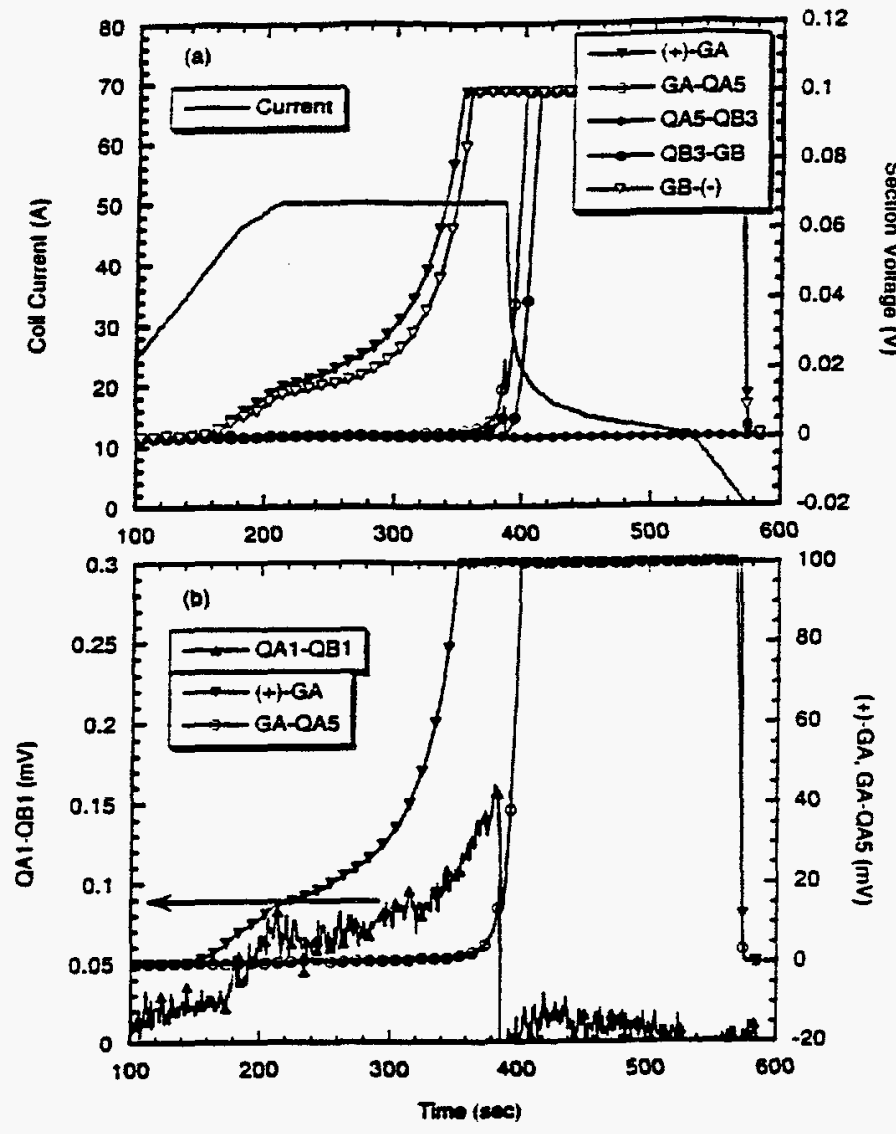

Fig 6 Voltage excursions of the five difierent cections of the coil in the same test run as is shown in Fig. 5 . The flat top of $0.1 \mathrm{~V}$ was due to amplifier saturation. Also shown in (b) is a closer look of the voltage over the innermost tum, QAlQB1.

It has now been widely accepted that the resistive transition of an HTS conductor is very broed, i.e., the n-value in the V-I power law is very low (often less than 10)." Thus, when an HTS conductor is charged above its $I_{e}$, it enters into a partially resistive state rather than a true normal state as in an LTS conductor. A significant amount of current remains in the HTS core instead of flowing out to the matrix. Therefore, the joule beating in a partially resistive "normal" zone in an HTS conductor is much reduced As this heat was spread throughout the coil, it heated up and drove more conductors into a partially resistive state, although their voltages could be too small to be measured. Thus, the coil quench was developed through the spreading of the joule heat, creating more low-resistance, partially resistive zones, and accelerated when most of the coil was far into the partially resistive state.

Thus, the development of a quench from a "normal zone" in an HTS coil would be much slowe than in an LTS coil. At the tested conductor current density of up to $3 \mathrm{kA} \mathrm{cm}^{2}$ (in the 2-tape conductor bundle), it took about $3 \mathrm{~min}$ to develop. Note that in the current charge shown in Fig. 3, the coil current was above the $I_{c}$ of the 1-tape section for about $200 \mathrm{~s}$ before the coil quenched.

Although the current test coil has a built-in lower $I_{c}$ ( 1 -tape conductor) section, lower $I_{c}$ sections are unavoidable in a superconducting coil. It exits at regions with intrinsically lower $I_{c}$ in the conductor, at regions of higher field, or at regions where the field is predominantly perpendicular to the face of the HTS tape. As heat is generated in a "normal zone" and is conducted throughout the coil, one can expect other "normal zones" to nucleate. Fig. $6(\mathrm{~b})$ shows that the innermost turn of the coil, QA1-QB1, also went into "normal" state $20 \mathrm{~s}$ after the single-tape outer turns section, (+)-GA. However, neither "normal" front made a distinctive propagation into the middle GA-QA5 section for the next $120 \mathrm{~s}$.

\section{CONCLUSION}

Stability and normal zone propagation experiments were performed on a double-pancake coil made of $\mathrm{Bi}-2223 / \mathrm{Ag}$ high temperature superconducting tape. The HTS coil was very stable against local pulse heating. As a matter of fact, no "nomal" zone was sustained or propagated with up to $18 \mathrm{~J}$ of puise heating.

However, spontaneous quenches of the coil occurred because the coil current was higher than that of the lower $I_{c}$ sections of the coil for a sufficiently long time. No sequential and distinctive "normal" front propagation was observed in the quench developing process. Rather, the quench behaved more like a spreading and continuous beating of an increasingly larger partially resistive section of the coil than like a "normal" front propagation.

Because of the high stability margin, one can expect an HTS coil not to suffer quenches from sudden heat release of wire motion or epoxy cracking as is often seen in an LTS coil. However, a delayed quench not common in an LTS coil may develop in an HTS coil that has undetected local weak spots. At a conductor current density of up to $3 \mathrm{kA} / \mathrm{cm}^{2}$, this process may take minutes to develop. Thus, a different quench detection technique and protection system may be needed for HTS coils.

\section{REFERENCES}

[1] R. A. Hawsey et al. "Progress in deveiopment of high temperature superconducting wire for electric power applications, paper presented at the 29th Int Energy Conversion Eng. Conf., Monterey, CA, Aug. 1994.

[2] A Otto et ah, "Multifilament Bi-2223 Tapes Made by a Metallic Precursor Route" IEEE Trans. Applied Superconductivity, Vol. 3, No. 1, p. 915 (1993).

[3] J. W. Lue et al. "Stability measuremerns on a 1-T high temperature superconducting magnet, to be published in IEEE Trans. Applied Superconductivity (1995).

[4] J. W. Lue et aL. Test resuits of two small high temperature superconducting coils," Adv. Cry. Eng., Vol. 40, p. 327 (1994). 